How Do We Encourage Gifted Girls to Pursue and Succeed in Science and Engineering?

Jilana S. Boston

Andrei Cimpian

New York University

In press, Gifted Child Today.

Acknowledgments

We thank Michael Barger, Joe Cimpian, Melis Muradoglu, Stacy Priniski, and Ken Smith for useful discussion and feedback on previous drafts of this manuscript. The writing of this manuscript was supported in part by National Science Foundation grant BCS-1733897 to A.C. Email: jilana.boston@,nyu.edu or andrei.cimpian@nyu.edu. 


\begin{abstract}
Despite having the raw ability to pursue careers in science and engineering, gifted girls often shy away from such careers. Here, we explore two explanations for this puzzling phenomenon. Specifically, we argue that exposure to (1) negative stereotypes about women's intellectual abilities and (2) stereotypes about scientists as "nerdy," eccentric loners may undermine gifted girls' confidence in their ability to succeed in science and engineering, their sense of belonging in these fields, and - ultimately - their interest. We also suggest evidence-based strategies for inoculating girls against these stereotypes and boosting their interest in science and engineering.
\end{abstract}




\section{How Do We Encourage Gifted Girls to Pursue and Succeed in Science and Engineering?}

Women remain underrepresented in many science and engineering fields. For example, only $23 \%$ of the PhDs conferred in engineering in 2015 went to women, and less than $20 \%$ of PhDs in computer science and physics (National Science Foundation, 2016). Since students in gifted and talented programs represent a critical talent pool for careers in science, engineering, technology, and mathematics (STEM; Heilbronner, 2011; National Science Board, 2010), one might expect a similar imbalance in the gender ratio of these programs. In reality, however, girls comprise approximately $51 \%$ of the gifted student population-a statistic that has not changed substantially in 15 years (United States Department of Education, 2000; National Association for Gifted Children, 2015).

The fact that girls and boys are equally represented among the nation's brightest children highlights a crucial point: The gender gaps in STEM disciplines are likely not due to gender differences in inherent cognitive abilities (see also Else-Quest, Hyde, \& Linn, 2010; Guiso, Monte, Sapienza, \& Zingales, 2008; Hyde \& Mertz, 2009; Penner, 2008; Spelke, 2005). The typical program for gifted and talented youth has quite stringent selection criteria (e.g., many programs include only youth with IQs above the $98^{\text {th }}$ percentile). By comparison, the average applicant to even the most mathematics-intensive STEM PhD programs scores only around the $75^{\text {th }}$ percentile on standardized tests of quantitative reasoning (Educational Testing Service, 2017; see also Ceci et al., 2014). Thus, gifted girls have the "raw ability" necessary to pursue STEM. Why, then, do they shy away from careers in this domain (e.g., Eccles, 1994; Kerr \& Multon, 2015; Lubinski, Benbow, \& Kell, 2014; Mendez \& Crawford, 2002)?

Here, we highlight two key factors that may contribute to this phenomenon-namely, children's exposure to (1) negative stereotypes about women's intellectual abilities, and (2) 
stereotypes about the people in STEM fields (e.g., "nerdy," socially awkward). Specifically, we review evidence of a relationship between (1) the negative stereotypes about women's intellectual abilities and girls' confidence, sense of belonging, and performance in STEM, and (2) the stereotypes about the people in STEM fields and girls' sense of belonging and interest in STEM. We should note at the outset that most of the research summarized here was not conducted on gifted children; however, the factors that we're describing involve broad cultural processes that are likely to apply to gifted and mainstream student populations alike.

Throughout, we will suggest concrete steps parents and teachers could take to help talented girls pursue and achieve success in STEM careers. These suggestions will follow from research on the key factors above and are intended to (1) inoculate girls against the effects of negative stereotypes concerning their abilities (e.g., by emphasizing a more malleable view of ability), and (2) challenge the prevailing stereotypes of the people and work involved in STEM fields (e.g., by presenting counter-stereotypical role models).

\section{Negative Stereotypes about Girls' Intellectual Abilities}

Across the globe, women are stereotyped positively on the dimension of warmth and nurturance, and negatively on the dimension of intellectual competence (e.g., Glick et al., 2000). A subset of the negative stereotypes about women's intellects are directly relevant to girls' pursuit of STEM: namely, (1) stereotypes about mathematical ability and (2) stereotypes about "brilliance" (i.e., exceptional intellectual ability in a more general sense). Both of these traits are generally thought to be prerequisites for success in STEM (e.g., Cimpian \& Leslie, 2015; Leslie, Cimpian, Meyer, \& Freeland, 2015; Meyer, Cimpian, \& Leslie, 2015), so the perception that girls lack these abilities is an obstacle to their advancement in this domain. And while it may be tempting to think that gifted girls would be immune to negative stereotypes about their 
intellectual abilities, this is unfortunately not the case. In fact, it is often the most talented members of stereotyped groups that are most affected by others' biased perceptions and, more generally, by signals suggesting that they may lack ability (e.g., Dweck, 2006; Keller, 2007; Licht \& Dweck, 1984; Licht, Linden, Brown, \& Sexton, 1984; Licht \& Shapiro, 1982; Osborne \& Walker, 2006; Snyder, Malin, Dent, \& Linnenbrink-Garcia, 2014; Spencer, Steele, \& Quinn, 1999).

In what follows, we provide a selective review of the evidence suggesting that these stereotypes are (1) acquired early in development and (2) undermine girls' self-efficacy (that is, confidence), belonging, and performance in STEM, with consequences for their success in this domain. We conclude this section by (3) suggesting potential means of buffering girls against these stereotypes.

1.1. Early Acquisition. Some of the stereotypes that hold girls back in STEM are acquired as early as first grade. For instance, Cvencek, Meltzoff, and Greenwald (2011) reported that children in the first and second grades already associate mathematics with boys and reading with girls, differences which tend to persist over time (Nagy et al., 2010) Similarly, elementaryschool girls typically draw a man when asked to draw a computer scientist (Hansen et al., 2017) or a mathematician (though they are more likely to draw a girl when the prompt is "child mathematician"; Steele, 2003). Reflecting women's increasing representation in scientific fields (e.g., Miller \& Wai, 2015), the likelihood of young girls drawing men as scientists has dropped in recent years, though they are still more likely to draw a male than a female scientist by the end of elementary school (Miller, Nolla, Eagly, \& Uttal, 2018). Beyond simply associating STEM with men, children seem to also believe that ability in this domain is a male trait (Del Río \& Strasser, 2013), and the same is true of technological skills such as programming and robotics 
(Master, Cheryan, Moscatelli, \& Meltzoff, 2017). Note, however, that some studies have found instead that young children favor their own gender when judging math and science abilities rather than showing a stereotype favoring males (Heyman \& Legare, 2004; Kurtz-Costes, Copping, Rowley, \& Kinlaw, 2014).

Children's notions of brilliance also become gendered at an early age. Bian, Leslie, and Cimpian (2017) investigated whether 5-, 6-, and 7-year-old children associate one gender more than the other with being "really, really smart" (a child-friendly equivalent of "brilliant"; see also Raty \& Snellman, 1997). While 5-year-old boys and girls both favored their own gender on this dimension, already at age 6 , girls were less likely than boys to identify members of their gender as "really, really smart." Interestingly, 6- and 7-year-old girls in this study also thought that girls get better grades in school than boys (which is actually true; Voyer \& Voyer, 2014)—a stark contrast with their judgments of who's “really, really smart.” In other words, children's judgments of brilliance were disconnected from one of the best sources of evidence in their environments regarding intellectual ability, which speaks to the tenuous link between stereotypes and reality.

Children's biases reflect the assumptions of the society in which they are growing up. Adults associate science and math with males more than females (e.g., Nosek et al., 2007), and as a result they tend to also perceive differences between boys' and girls' abilities, even when there aren't any. For instance, parents often think that math and science are harder for their daughters than for their sons, even when the daughters get similar or higher grades than the sons in these subjects (e.g., Jacobs, 1991; Tenenbaum \& Leaper, 2003). Similarly, teachers rate the mathematical abilities of boys to be higher relative to those of girls with similar grades and behaviors (e.g., J. Cimpian, Lubienski, Timmer, Makowski, \& Miller, 2016; Robinson-Cimpian, 
Lubienski, Ganley, \& Copur-Gencturk, 2014). Given children's fine-tuned sensitivity to signals in their social environments (e.g., Chestnut \& Markman, 2016; Cimpian, Arce, Markman, \& Dweck, 2007; Skinner, Meltzoff, \& Olson, 2017), it is not surprising that they quickly pick up on what the people around them think about boys' and girls' mathematical talent.

Clues about whom society views as brilliant (in a general sense, not restricted to a domain) are available in children's environments as well. For example, parents in the US are more than twice as likely to search Google for whether their sons are geniuses than for whether their daughters are (Stephens-Davidowitz, 2014); in contrast, searches that focus on physical traits are more common for daughters (e.g., "is my daughter ugly?" is $160 \%$ more frequent than “is my son ugly?"). Teachers likely have differential expectations of their male and female students as well. For example, the teachers in a study by Bianco, Harris, Garrison-Wade, and Leech (2011) were provided with identical information about a hypothetical male or female student and asked a number of questions, including — crucially—whether they would refer the child to the gifted program in their school. Teachers were significantly more likely to refer the male than the female student to gifted services, despite the identical descriptions. Teachers just did not "see" as much brilliance in the girl; one even commented, "it seems this young girl is intelligent, creative, and a good critical thinker, however not necessarily a genius!” (p. 175). Thus, well into the $21^{\text {st }}$ century, parents and teachers are still forming different expectations for boys' and girls' intellectual abilities. These expectations then "spill out" in adults' behavior toward children, clueing them into the broader gender stereotypes of their culture (e.g., Chang, Sandhofer, \& Brown, 2011; Crowley, Callanan, Tenenbaum, \& Allen, 2001; Fagot, Leinbach, \& O’Boyle, 1992).

The evidence reviewed so far suggests that, from a young age, children are familiar with 
the cultural stereotypes that portray mathematical talent, as well as exceptional intellectual talent more broadly conceived, as male traits. These stereotypes are likely to undermine girls' success in STEM pursuits, as we review next.

1.2. Relation to Self-Efficacy, Sense of Belonging, and Performance in STEM. To the extent that girls internalize the negative stereotypes about their gender's intellectual abilities, they may feel less competent in STEM than they actually are (e.g., Correll, 2001, 2004;

Schmader, Johns, \& Barquissau, 2004). In other words, these stereotypes may lower girls' STEM self-efficacy — their confidence that they can succeed in this domain (e.g., Bandura, 1977, 1982;

Eccles, 1994). Self-efficacy is one of the main factors that guide career choices - all other things equal, people tend to pursue careers that they expect they'll be good at (e.g., Eccles, 1994; McClelland, 1985; Wigfield \& Eccles, 2000). There is extensive evidence that girls have lower self-efficacy than boys with respect to mathematics, even when they get similar grades (for a recent review, see Huang, 2013). In turn, girls' lower-self efficacy in this domain steers their career-relevant decisions (e.g., the courses they take) away from STEM (e.g., Betz \& Hackett, 1986; Correll, 2001, 2004; Eccles, 1994; Schmader et al., 2004; Simpkins, Davis-Keen, \& Eccles, 2006).

A recent study illustrates this early link between ability stereotypes and children's decision-making in this domain. Bian et al. (2017) introduced 5- to 7-year-olds to an unfamiliar game-like activity that was described as being for "children who are really, really smart" and then asked children whether they wanted to do this activity. At the age of 5, when girls' confidence in their gender's brilliance is typically still high, their desire to do the activity matched boys'. Six- and 7-year-old girls, however, were less likely to engage in this activity than same-age boys were. The fact that this is also the age at which girls' ideas about who is brilliant 
change is more than a coincidence - children's growing endorsement of the "brilliance = males" stereotype was correlated with the gender difference in their activity choices. Note too that when the exact same activities were described as being for "children who try really, really hard," boys and girls didn't differ in their attitudes toward them; it was the act of portraying the activities as being for "really, really smart" children that undermined girls' motivation. Although more evidence is needed to establish the generalizability of this phenomenon, this finding hints at the cumulative processes by which stereotypes about brilliance may, over time, erode young women's confidence in their ability to succeed in STEM careers (e.g., Bian, Leslie, Murphy, \& Cimpian, in press), which are generally perceived to require the brilliance girls are stereotyped as lacking (e.g., Meyer \& Leslie, 2015; Storage, Horne, Cimpian, \& Leslie, 2016).

So far, we have discussed what happens when girls internalize stereotypes. Importantly, however, the stereotypes that associate intellectual talent with males may affect even girls who don't believe these stereotypes. Under certain circumstances, simply being aware that these stereotypes exist can be detrimental by undermining girls' (1) sense of belonging in STEM and (2) their ability to perform at their best.

The extent to which a student feels that they belong in a field - that they fit in with others (e.g., peers, instructors) and are respected and valued by them—is an important predictor of whether the student persists in that field (e.g., Dennehy \& Dasgupta, 2017; Good, Rattan, \& Dweck, 2012; Walton \& Cohen, 2007). This sense of being valued is more fragile when stereotypes are "in the air" (Steele, 1997)—when it is possible that others' views of the student are shaped by stereotypes about her group (regardless of whether she herself endorses the stereotypes). For example, imagine how a boy and a girl might view something as innocuousseeming as a teacher's offer of help in a math class. Whether he accepts the offer or not, for the 
boy this offer probably carries little meaning beyond this specific interaction with the teacher; for the girl, however, the same offer might mean something more — it might signal that others assume students like her to find this environment too challenging. ${ }^{1}$ The threat of being stereotyped weakens girls' sense of being accepted by others in STEM contexts, and as a result often reduces their motivation to pursue careers in STEM (e.g., Dasgupta, 2011; Good et al., 2012). Consistent with this notion, Good et al. (2012) found that female students who perceived others in their math class to believe that women have less inherent math ability than men reported a decrease in their sense of belonging over the course of the semester and, in turn, lower intention to take other math classes in the future (see also Rattan et al., 2017).

The possibility of being stereotyped threatens not only girls' sense of belonging in STEM but also their performance (e.g., Spencer, Logel, \& Davies, 2016). Children's awareness of these stereotypes seems to affect their test-taking abilities even as early as age 6 (e.g., Galdi, Cadinu, \& Tomasetto, 2014; for a review, see Régner, Steele, Ambady, Thinus-Blanc, \& Huguet, 2014). When students taking a test worry about whether others will judge their performance through the lens of negative stereotypes, they are in effect doing two things at once: working on the test and wondering how they are doing and whether they are at risk of confirming the negative stereotype about their group (e.g., Schmader, Johns, \& Forbes, 2008). (Many might be doing a third thing as well, which is trying to suppress the worries about their performance so that they can concentrate on the test.) These intrusive, stereotype-triggered thoughts take a toll on students' performance, preventing them from doing as well as they could (e.g., Flore \& Wicherts, 2015; Nguyen \& Ryan, 2008). Even the seemingly innocuous step of reporting one's gender before taking a math

\footnotetext{
${ }^{1}$ To avoid this impression, a teacher might choose to normalize the student's difficulty (e.g., "Everyone needs help with this material at first"; Walton \& Cohen, 2011) and express high expectations (e.g., "I'm helping you because I know that you can do really well in this class"; Yeager et al., 2014).
} 
test sometimes impairs the performance of female students (Danaher \& Crandall, 2008). And this all matters, of course, because underperforming relative to one's potential is not just frustrating — it actually makes it more difficult to succeed in a field and may lead many talented girls to look elsewhere (e.g., Steele, 1997).

In summary, we have highlighted three of the ways in which the negative stereotypes about women's intellectual abilities might steer gifted girls away from careers in STEM: These stereotypes cause girls to (1) doubt their abilities in the STEM domain, to (2) feel they don't belong there, and to (3) underperform. We go on to discuss research suggesting how we might try to alleviate the effects of these ability stereotypes.

1.3. What Can We Do? Because stereotypes are woven into the fabric of our culture (e.g., Caliskan, Bryson, \& Narayanan, 2017) and can affect students by their mere presence, there is likely no silver bullet—no failsafe way of shielding girls from them. Prior research suggests strategies that might help; they all have potential pitfalls, but they nevertheless provide a solid basis for action. These strategies can be grouped into two categories, depending on whether they intervene on girls' beliefs about their own abilities or on girls' perceptions of STEM environments (for a summary, see Table 1).

1.3.1. Changing Girls' Beliefs. One potential strategy is to inoculate girls against the negative stereotypes about their abilities. Two such "psychological vaccines," both of which have the potential to reduce the effects of being stereotyped, are (1) instilling a growth mindset in girls (e.g., Dweck, 2006) and (2) exposing them to successful female role models (e.g., Dasgupta, 2011).

1.3.1.1. Growth Mindsets. Stereotypes suggest that some groups have more inherent ability than others and are more successful as a result. Thus, the logic of stereotypes rests on the 
assumption that inherent ability is essential for success. Adopting what is known as a growth mindset negates this assumption, thereby reducing the relevance of stereotypes. A growth mindset is the belief that one's abilities in a domain (such as STEM) can be improved with consistent effort, effective strategies, and guidance from teachers and mentors (e.g., Dweck, 2006). Students who adopt a growth mindset view success as emerging from these specific processes rather than as depending on the amount of fixed, inherent ability one was supposedly born with (which is what so-called fixed mindsets portray as most important). In addition, because anyone can engage in these processes, growth mindsets offer a concrete path toward improvement and success for students regardless of gender or race. Indeed, growth mindset interventions have improved girls' performance in mathematics (Good, Aronson, \& Inzlicht, 2003) and, more generally, the academic outcomes of students from a range of stereotyped groups (Yeager et al., 2016a).

Although growth mindsets are likely to buffer gifted girls against stereotypes, the process of instilling these mindsets in children is not without its challenges (e.g., Yeager et al., 2016b). For instance, it is important to clarify that effort and strategies aren't intended to somehow compensate for lack of ability; if gifted girls infer that they have to work harder than boys to succeed in STEM, their self-efficacy and belonging will likely suffer (Smith, Lewis, Hawthorne, \& Hodges, 2013; see also Ziegler \& Heller, 2000). The key to a successful growth mindset intervention is to convey that effort and strategies build ability, and that this is true for everyone (which helps to normalize effort and block the inference that effort is a sign of low ability). For example, a teacher might say, "If you want to become good at math, there's no other way than by doing a lot of problems, especially hard ones that you can learn from. Everyone has to do this!" In trying to foster a growth mindset, teachers and parents might also want to be mindful 
of the natural tendency to treat children's mistakes as something to be avoided and brushed under the carpet when they occur. From a growth-mindset perspective, mistakes are actually a valuable source of information about which skills need work (e.g., "Mistakes are good because they show you what you don't understand yet!'). A hallmark of an authentic growth mindset is seeing failure as a learning opportunity, and parents who adopt a positive, constructive attitude toward failure are more likely to have growth-oriented children (Haimovitz \& Dweck, 2016). However, having a positive attitude toward failure doesn't just mean telling children to "try again" or "work harder next time" (e.g., Gross-Loh, 2016). The focus always needs to be on the learning process — on discovering where children's mistakes are coming from and helping them come up with strategies that improve their understanding (e.g., "You made a mistake—-that's great! Let's see why and figure out what you can do differently next time!"). Trying the same thing over and over won't achieve much. Children's effort needs to be channeled (with adults' help) into the discovery of better, deeper ways of thinking about the material. When children see how their efforts have paid off, they will be particularly likely to adopt a growth mindset themselves.

1.3.1.2. Role Models. Exposing gifted girls to examples of women who have achieved success in STEM may also serve to inoculate them against ability stereotypes. Specifically, seeing other members of their gender pursue successful careers in this domain may bolster girls' confidence in their own abilities (i.e., their self-efficacy) and lessen their concerns about being stereotyped; in turn, reducing the threat of negative stereotypes may increase girls' sense of belonging in this field and improve their performance (e.g., Dasgupta, 2011; Else-Quest et al., 2010). Here as well, however, it is important to be mindful of the potential pitfalls. Not every role model is inspiring, and some can even be demotivating. The more similar the role models 
are to the girls (in terms of, e.g., background and life history), the more likely the girls are to identify with these women, and thus the more attainable their success will seem. Girls may be more motivated to become like their role models if they can easily envision following a similar trajectory to success (Oyserman \& James, 2009). In a sense, what the role models do is help girls project themselves into the future. To the extent that girls' perception of their present self is similar to their perception of the available proxy for their future self (i.e., the role model), they will see a clear path forward and will feel motivated (e.g., Oyserman, Terry, \& Bybee, 2002). However, if the role model is too different or if her success feels beyond what many people can reasonably achieve (consider, e.g., Marie Curie's two Nobel prizes), the net effect might be to make a career in STEM feels even less plausible than before (e.g., Betz \& Sekaquaptewa, 2014).

1.3.2. Changing the STEM Environment. Both of the strategies described so far involve intervening on girls' belief systems - altering their beliefs about success and their expectations for the future, respectively. However, one can also try to lessen the impact of the negative stereotypes about women's intellectual abilities by changing the environment in STEM fields.

One way of creating more identity-safe environments is to acknowledge the reality of stereotypes but deny their validity (e.g., Davies, Spencer, \& Steele, 2005). For example, STEM teachers who are explicit about the fact that they expect boys and girls to do equally well in their classes might "clear the air" of the noxious stereotypes that threaten girls' belonging and performance. Again, however, the details of how these expectations are conveyed matter: Some seemingly egalitarian statements might actually send the wrong message. For example, saying that "girls are as good as boys at math" or "girls are as smart as boys" implies that boys are the prototype — the reference point against which girls must be compared — which actually reinforces the idea that boys are more capable (e.g., Chestnut \& Markman, 2016). To avoid this problematic 
subtext, parents and teachers should use statements that place boys and girls on an equal footing, down to the level of syntax — for example, "girls and boys are equally good at math" or "there is no difference in how smart boys and girls are."

Strategies for changing the STEM environment can even go as far as informing students about the potential effects of stereotype threat on girls' performance: Johns, Schmader, and Martens (2005) found that teaching female college students that stereotypes might make them feel anxious and impair their performance actually improved their performance on a math test (see also Bigler \& Wright, 2014).

It is also important to think carefully about the physical environment and the cues it sends to male and female students (e.g., Cheryan et al., 2009). Even though it might seem trivial, something as simple as a few portraits of female scientists hung around the classroom may lessen the threat that female students typically experience in such settings, serving as a reminder that people like them can succeed in STEM.

Another way of challenging girls' perception of being less capable in STEM is to provide them with low-stakes, non-diagnostic opportunities to succeed in this domain. For example, after a 20-minute programming session that was framed as a game, 6-year-old girls felt more motivated and capable with regard to technology (even though their reported stereotypes did not change; Master et al., 2017). Importantly, brief experiences such as these have the potential to set in motion recursive processes - chain reactions of positive thoughts and emotions that, over time, can produce substantial changes in one's attitudes toward a domain (e.g., Walton, 2014; Yeager \& Walton, 2011). One positive experience with programming, no matter how brief, might make it more likely for a girl to pursue other opportunities to program, which in turn might reinforce her confidence in her programming abilities, and so on. 


\section{Stereotypes About the People in STEM}

When contemplating career options, many people ask themselves, "What kind of person works in this field?" and then, “Am I that kind of person?” (e.g., Cheryan \& Plaut, 2010; Niedenthal, Cantor, \& Kihlstrom, 1985). If the answer to the second question is "no," then the field is seldom considered further. In other words, a mismatch between a young person's selfconcept (e.g., "I like working with people") and their stereotypes about the members of a particular field (e.g., "they're loners") will make that field seem like an unattractive career option. Unfortunately, this process works against girls' joining STEM fields. Widely held stereotypes of scientists portray them as conducting solitary (vs. collaborative) work in pursuit of self-centered goals such as satisfying their curiosity or achieving recognition (vs. altruistic goals such as helping others; e.g., Diekman, Steinberg, Brown, Belanger, \& Clark, 2017). STEM workers are also assumed to share a specific personality profile: introverted, socially awkward, unemotional, eccentric, "nerdy" or "geeky", obsessed with their work, and detached from reality (e.g., American Association of University Women, 2000; Cheryan, Master, \& Meltzoff, 2015; Cheryan, Ziegler, Montoya, \& Jiang, 2017; Losh, 2010; Mercier, Barron, \& O’Connor, 2006; Pansegrau, 2008; Romnes, Overbeek, Scholte, Engels, \& De Kemp, 2007; Schott \& Selwyn, 2000). These perceptions of STEM act as a gender-specific deterrent: Girls are socialized to see themselves as different from the "prototypical" scientist on most of these dimensions (e.g., Eccles, Jacobs, \& Harold, 1990; Fivush, Brotman, Buckner, \& Goodman, 2000; Leaper, 2002; but see Endendijk et al., 2016), and adult women continue to report self-views that are inconsistent with this prototype (e.g., Battle \& Wigfield, 2003; Su, Rounds, \& Armstrong, 2009). This mismatch may be especially potent for girls who are academically gifted, as they are likely to be talented in multiple domains (Park, Lubinski, \& Benbow, 2008). For them, having the 
ability to succeed in other fields may simplify the decision to opt out of STEM, especially since they may also feel a greater sense of belonging in these other fields (Wang, Eccles, \& Kenny, 2013).

In what follows, we briefly review evidence on (1) the acquisition of the stereotypes about people in STEM, (2) the relation of these stereotypes to girls' aspirations, and (3) potential means of counteracting them.

2.1. Early Acquisition. Stereotypes of scientists and engineers seem to be acquired as early as the negative stereotypes about women's intellectual abilities: around the time when children enter elementary school. Although developmental studies haven't explored all elements of these stereotypes, the evidence nevertheless suggests that young children all over the world tend to see scientists and engineers as lonely, selfish, boring (although sometimes also dangerous), eccentric_ — and mostly male (e.g., Capobianco, Diefes-dux, Mena, \& Weller, 2011; Hillman et al., 2014; Koren \& Bar, 2009; Losh, Wilke, \& Pop, 2008; Newton \& Newton, 1992, 1998; Song \& Kim, 1999).

Children's self-concepts are already gendered by the time children acquire these stereotypes about scientists and engineers (e.g., Martin \& Ruble, 2004), which means that—right from the start - STEM jobs will be inconsistent with how many girls see themselves. Consider, for example, the notion that scientists put in long, solitary hours to research some arcane problem that few people care about. In contrast, 6- and 7-year-old girls already conceive of their gender as sociable, nurturing, and other-oriented: Girls this age, for instance, are significantly more likely than boys to assume that members of their gender "like to help others with their problems and are friendly to everyone" (Bian et al., 2017). It's easy to see how a career in science would be unappealing to many young girls, given how they're typically raised to think of themselves and 
the (largely false) impressions they have of scientists.

2.2. Relation to Sense of Belonging and Interest in STEM. Due to the common stereotypes of scientists as antisocial eccentrics, girls and young women often feel dissimilar to (what they believe to be) the typical STEM professional. This sense of being different leads girls to anticipate a lack of fit or belonging in these fields, which in turn lowers girls' interest in them (e.g., Cheryan et al., 2009; Cheryan \& Plaut, 2010; Diekman et al., 2017; Heilman, 2012).

To illustrate, Cheryan and Plaut (2010) found that the gender difference in college students' interest in computer science was best explained by the gender difference in students' perceived similarity to computer science majors. In other words, young women's expectation that they wouldn't fit in with others in computer science was the strongest reason for their lack of interest in this field — stronger than their worries about whether they'd able to succeed, or about whether they would experience prejudice (but see Ganley, George, J. Cimpian, \& Makowski, in press). Even subtle reminders of the stereotypes about STEM can trigger a negative reaction among girls. For example, when girls in high school saw a photograph of a computer science classroom that contained video games, Star Trek posters, and a few other objects that evoked the image of the nerdy, socially awkward computer scientist, their anticipated sense of belonging was lower than when the same classroom was furnished with more neutral objects (e.g., coffee maker, plants; Master, Cheryan, \& Meltzoff, 2016). (This experimental manipulation had no effect on boys' belonging.) Due to their lower sense of belonging, the girls who had been shown the stereotypical classroom also reported less interest in taking the computer science class offered in it.

Although more research is needed to explore these processes in younger children and a wider range of STEM fields, the evidence to date points to stereotypes about the people in STEM 
as a major obstacle to talented girls' participation in these fields.

2.3. What Can We Do? To counteract the effects of stereotypes about the people in STEM, we have to show children that these stereotypes are false. Many modern scientists and engineers work collaboratively toward solving problems of great societal significance (e.g., National Academy of Engineering, 2017); they are not detached from the world, nor are they the pocket-protector-wearing, absent-minded types that Hollywood makes them out to be (e.g., Pansegrau, 2008). Although trying to go against the grain of societal stereotypes might seem like an impossible challenge, the studies on this topic suggest that young people's stereotypes of STEM professionals are malleable enough that this is in fact a viable solution (e.g., Master et al., 2016). In particular, parents and teachers can work to revise the stereotypical images of (1) scientists and engineers as people and (2) the work they do (see Table 1 for a summary).

\subsubsection{Revising the Stereotypes of Scientists and Engineers as People. Exposure to} scientists and engineers who don't fit the mold of the geeky, eccentric loner might provide a long-lasting boost to girls' interest in STEM. For example, when undergraduate women interacted with a computer science major who didn't conform to this stereotype (e.g., whose hobbies were playing sports, hanging out with friends, and listening to music), they expressed greater interest in majoring in this field than when they interacted with a more stereotypical major, both immediately after the interaction and two weeks later (Cheryan, Drury, \& Vichayapai, 2013; but see Weisgram \& Bigler, 2006; 2007). Similarly, 13- to 15-year-old students reported revising their initial conception of scientists from "boring" and "nerdy" to a more favorable impression after brief interactions with career scientists (Woods-Townsend et al., 2015). It is noteworthy that these changes tend to occur regardless of whether the nonstereotypical role model is a man or a woman. Thus, the key to revising children's ideas about 
scientists via role models may be to identify ones who are relatable and dissimilar to the prevailing stereotypes of people in STEM, regardless of their gender (Cheryan, Siy, Vichayapai, Drury, \& Kim, 2011).

To extrapolate from these results, it is possible that exposing young girls regularly to information about actual STEM professionals, the vast majority of whom don't fit the "eccentric loner" personality profile, might alleviate girls' concerns about not fitting in. For example, parents and teachers could encourage girls to explore resources that portray STEM professionals in a non-stereotyped manner (such as the website This is What a Scientist Looks Like,

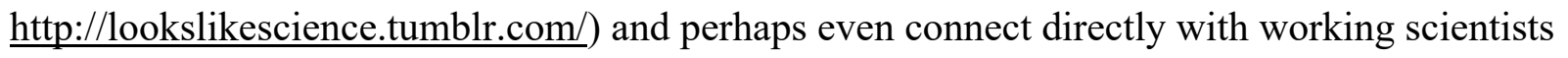
(e.g., through online mentoring programs; Stoeger, Duan, Schirner, Greindl, \& Ziegler, 2013).

2.3.2. Revising the Stereotypes of the Work that Scientists and Engineers Do. It is also important to fight the notion that science does not serve communal, other-oriented goals. For example, framing a scientist's job as involving working with other people and helping them solve problems (as opposed to working and solving problems alone) led to an increased positivity toward a career in science among undergraduate students of both genders (Clark, Fuesting, \& Diekman, 2016; see also Brown, Smith, Thoman, Allen, \& Muragishi, 2015). The gender neutrality of this result is important. Highlighting the altruistic nature of scientific activity is unlikely to preclude boys' interest; rather, boys and girls may both become more motivated to pursue STEM when they consider a deeper purpose for learning these subjects (see also Harackiewicz, Canning, Tibbetts, Priniski, \& Hyde, 2016; Harackiewicz, Rozek, Hulleman, \& Hyde, 2012; Hulleman \& Harackiewicz, 2009). Additional support for the suggestion to portray science as a communal activity comes from a recent study with preschoolers: Four-year-old boys and girls who were led to believe that they were performing science-relevant tasks as part of a 
group showed higher self-efficacy and greater enjoyment than children who thought they were performing the same tasks as individuals (Master, Cheryan, \& Meltzoff, 2017).

These findings point to the potential value of encouraging girls to consider how research in STEM may be applied in daily life and in helping others. Providing girls with realistic, everyday examples of the usefulness of science and math, as well as asking them to generate their own examples, may be effective in capturing the interest of many girls who might not otherwise see these subjects as something they would ever want to pursue (Canning \& Harackiewicz, 2015).

\section{Conclusion}

In the debates about women's underrepresentation in STEM, one common viewpoint is that underrepresentation is not, in and of itself, evidence that something's gone wrong (e.g., Hakim, 2006). Perhaps girls and boys just have different preferences, and that's why they orient toward different careers - why should we try to force girls into careers they don't want? Developmental evidence reveals one problem with such arguments: Whereas adult women might indeed report different preferences than adult men (e.g., Su et al., 2009), there is little reason to believe that these are hard-wired preferences and much to suggest the opposite. As members of an intensely social species, human children use the beliefs of their culture to inform how they should live their lives (e.g., Roberts, Gelman, \& Ho, 2017; Schmidt, Butler, Heinz, \& Tomasello, 2016). The evidence reviewed here suggests that exposure to cultural stereotypes about women's intellectual abilities and about the people in STEM leads boys and girls to develop preferences that they may not have had otherwise. In sending these messages, our culture needlessly limits the career options that boys and girls consider, whether they are gifted or not. It is up to all of us to fix the environment in which children decide what they would like to be when they grow up. 


\section{References}

American Association of University Women. (2000). Tech-Savvy: Educating Girls in the New Computer Age. Retrieved from http://history.aauw.org/files/2013/01/ TechSavvy.pdf

Bandura, A. (1977). Self-efficacy: Toward a unifying theory of behavioral change. Psychological Review, 84, 191-215.

Bandura, A. (1982). Self-efficacy mechanism in human agency. American Psychologist, 37, 122147.

Battle, A., \& Wigfield, A. (2003). College women's value orientations toward family, career, and graduate school. Journal of Vocational Behavior, 62, 56-75.

Benbow, C. P. (2012). Identifying and nurturing future innovators in science, technology, engineering, and mathematics: A review of findings from the study of mathematically precocious youth. Peabody Journal of Education, 87, 16-25.

Betz, N. E., \& Hackett, G. (1986). Applications of self-efficacy theory to understanding career choice behavior. Journal of Social and Clinical Psychology, 4, 279-289.

Betz, D. E., \& Sekaquaptewa, D. (2012). My fair physicist? Feminine math and science role models demotivate young girls. Social Psychological and Personality Science, 3, 738 746.

Bian, Leslie, S. J., \& Cimpian, A. (2017). Gender stereotypes about intellectual ability emerge early and influence children's interests. Science, 355, 389-391.

Bian, L., Leslie, S. J., Murphy, M. C., \& Cimpian, A. (in press). Messages about brilliance undermine women's interest in educational and professional opportunities. Journal of Experimental Social Psychology. https://doi.org/10.1016/j.jesp.2017.11.006 
Bianco, M., Harris, B., Garrison-Wade, D., \& Leech, N. (2011). Gifted girls: Gender bias in gifted referrals. Roeper Review, 33, 170-181.

Bigler, R. S., \& Wright, Y. F. (2014). Reading, writing, arithmetic, and racism? Risks and benefits to teaching children about intergroup biases. Child Development Perspectives, 8 , $18-23$.

Brown, E. R., Smith, J. L., Thoman, D. B., Allen, J. M., \& Muragishi, G. (2015). From bench to bedside: A communal utility value intervention to enhance students' biomedical science motivation. Journal of Educational Psychology, 107, 1116-1135.

Caliskan, A., Bryson, J. J., \& Narayanan, A. (2017). Semantics derived automatically from language corpora contain human-like biases. Science, 356, 183-186.

Canning, E. A., \& Harackiewicz, J. M. (2015). Teach it, don't preach it: The differential effects of directly-communicated and self-generated utility-value information. Motivation Science, $1,47$.

Capobianco, B. M., Diefes-dux, H. A., Mena, I., \& Weller, J. (2011). What is an engineer? Implications of elementary school student conceptions for engineering education. Journal of Engineering Education, 100, 304-328.

Ceci, S. J., Ginther, D. K., Kahn, S., \& Williams, W. M. (2014). Women in academic science: A changing landscape. Psychological Science in the Public Interest, 15, 75-141.

Chang, A., Sandhofer, C. M., \& Brown, C. S. (2011). Gender biases in early number exposure to preschool-aged children. Journal of Language and Social Psychology, 30, 440-450.

Cheryan, S., Drury, B. J., \& Vichayapai, M. (2013). Enduring influence of stereotypical computer science role models on women's academic aspirations. Psychology of Women Quarterly, 37, 72-79. 
Cheryan, S., Master, A., \& Meltzoff, A. N. (2015). Cultural stereotypes as gatekeepers: Increasing girls' interest in computer science and engineering by diversifying stereotypes. Frontiers in Psychology, 6, 1-8.

Cheryan, S., \& Plaut, V. C. (2010). Explaining underrepresentation: A theory of precluded interest. Sex Roles, 63, 475-488.

Cheryan, S., Plaut, V. C., Davies, P. G., \& Steele, C. M. (2009). Ambient belonging: How stereotypical cues impact gender participation in computer science. Journal of Personality and Social Psychology, 97, 1045-1060.

Cheryan, S., Siy, J. O., Vichayapai, M., Drury, B. J., \& Kim, S. (2011). Do female and male role models who embody STEM stereotypes hinder women's anticipated success in STEM?. Social Psychological and Personality Science, 2, 656-664.

Cheryan, S., Ziegler, S. A., Montoya, A. K., \& Jiang, L. (2017). Why are some STEM fields more gender balanced than others? Psychological Bulletin, 143, 1-35.

Chestnut, E. K., \& Markman, E. M. (2016). Are horses like zebras, or vice versa? Children's sensitivity to the asymmetries of directional comparisons. Child Development, 87,568 582.

Cimpian, A., Arce, H. M. C., Markman, E. M., \& Dweck, C. S. (2007). Subtle linguistic cues affect children's motivation. Psychological Science, 18, 314-316.

Cimpian, A., \& Erickson, L. C. (2012). The effect of generic statements on children's causal attributions: Questions of mechanism. Developmental Psychology, 48(1), 159-170.

Cimpian, A., \& Leslie, S. J. (2015). Response to comment on "Expectations of brilliance underlie gender distributions across academic disciplines”. Science, 349, 391-391.

Cimpian, J. R., Lubienski, S. T., Timmer, J. D., Makowski, M. B., \& Miller, E. K. (2016). Have 
gender gaps in math closed? Achievement, teacher perceptions, and learning behaviors across two ECLS-K cohorts. AERA Open, 2, 1-19.

Clark, E. K., Fuesting, M. A., \& Diekman, A. B. (2016). Enhancing interest in science: Exemplars as cues to communal affordances of science. Journal of Applied Social Psychology, 46, 641-654.

Correll, S. J. (2001). Gender and the career choice process: The role of biased self-assessments. American Journal of Sociology, 106, 1691-1730.

Correll, S. J. (2004). Constraints into preferences: Gender, status, and emerging career aspirations. American Sociological Review, 69, 93-113.

Crowley, K., Callanan, M. A., Tenenbaum, H. R., \& Allen, E. (2001). Parents explain more often to boys than to girls during shared scientific thinking. Psychological Science, 12, 258261.

Cvencek, D., Meltzoff, A. N., \& Greenwald, A. G. (2011). Math-gender stereotypes in elementary school children. Child Development, 82, 766-779.

Danaher, K., \& Crandall, C. S. (2008). Stereotype threat in applied settings re-examined. Journal of Applied Social Psychology, 38, 1639-1655.

Dasgupta, N. (2011). Ingroup experts and peers as social vaccines who inoculate the selfconcept: The stereotype inoculation model. Psychological Inquiry, 22, 231-246.

Davies, P. G., Spencer, S. J., \& Steele, C. M. (2005). Clearing the air: Identity safety moderates the effects of stereotype threat on women's leadership aspirations. Journal of Personality and Social Psychology, 88, 276-287.

Del Río, M. F., \& Strasser, K. (2013). Preschool children's beliefs about gender differences in academic skills. Sex Roles, 68, 231-238. 
Dennehy, T. C., \& Dasgupta, N. (2017). Female peer mentors early in college increase women's positive academic experiences and retention in engineering. Proceedings of the National Academy of Sciences, 114, 5964-5969.

Diekman, A. B., Steinberg, M., Brown, E. R., Belanger, A. L., \& Clark, E. K. (2017). A goal congruity model of role entry, engagement, and exit: Understanding communal goal processes in STEM gender gaps. Personality and Social Psychology Review, 21, 142175.

Dweck, C. S. (2006). Mindsets. The psychology of success. New York, NY: Ballantine.

Eccles, J. S. (1994). Understanding women's educational and occupational choices. Psychology of Women Quarterly, 18, 585-609.

Eccles, J. S., Jacobs, J. E., \& Harold, R. D. (1990). Gender role stereotypes, expectancy effects, and parents' socialization of gender differences. Journal of Social Issues, 46, 183-201.

Educational Testing Service. (2017). Guide to the Use of Scores. Retrieved from http://www.ets.org/s/gre/pdf/gre_guide.pdf.

Else-Quest, N. M., Hyde, J. S., \& Linn, M. C. (2010). Cross-national patterns of gender differences in mathematics: A meta-analysis. Psychological Bulletin, 136, 103-127.

Endendijk, J. J., Groeneveld, M. G., Bakermans-Kranenburg, M. J., \& Mesman, J. (2016). Gender-differentiated parenting revisited: Meta-analysis reveals very few differences in parental control of boys and girls. PLOS ONE, 11, 1-33.

Fivush, R., Brotman, M. A., Buckner, J. P., \& Goodman, S. H. (2000). Gender differences in parent-child emotion narratives. Sex Roles, 42, 233-253.

Flore, P. C., \& Wicherts, J. M. (2015). Does stereotype threat influence performance of girls in stereotyped domains? A meta-analysis. Journal of School Psychology, 53, 25-44. 
Galdi, S., Cadinu, M., \& Tomasetto, C. (2014). The roots of stereotype threat: When automatic associations disrupt girls' math performance. Child Development, 85, 250-263.

Ganley, C. M., George, C. E., Cimpian, J. R., \& Makowski, M. B. (in press). Gender Equity in College Majors: Looking Beyond the STEM/Non-STEM Dichotomy for Answers Regarding Female Participation. American Educational Research Journal. https://doi.org/10.3102/0002831217740221

Gelman, S. A. (2003). The essential child: Origins of essentialism in everyday thought. New York: Oxford University Press.

Glick, P., Fiske, S. T., Mladinic, A., Saiz, J. L., Abrams, D., Masser, B., ... \& Annetje, B. (2000). Beyond prejudice as simple antipathy: Hostile and benevolent sexism across cultures. Journal of Personality and Social Psychology, 79, 763-775.

Good, C., Aronson, J., \& Inzlicht, M. (2003). Improving adolescents' standardized test performance: An intervention to reduce the effects of stereotype threat. Journal of Applied Developmental Psychology, 24, 645-662.

Good, C., Rattan, A., \& Dweck, C. S. (2012). Why do women opt out? Sense of belonging and women's representation in mathematics. Journal of Personality and Social Psychology, 102, 700-717.

Guiso, L., Monte, F., Sapienza, P., \& Zingales, L. (2008). Culture, gender, and math. Science, 320, 1164-1165.

Gross-Loh, C. (2016, December 16). How praise became a consolation prize: Helping children confront challenges requires a more nuanced understanding of the "growth mindset." The Atlantic. Retrieved from https://www.theatlantic.com/education/archive/2016/12/howpraise-became-a-consolation-prize/510845/ 
Haimovitz, K., \& Dweck, C. S. (2016). Parents' views of failure predict children's fixed and growth intelligence mind-sets. Psychological Science, 27, 859-869.

Hakim, C. (2006). Women, careers, and work-life preferences. British Journal of Guidance \& Counselling, 34, 279-294.

Hansen, A. K., Dwyer, H. A., Iveland, A., Talesfore, M., Wright, L., Harlow, D. B., \& Franklin, D. (2017). Assessing children's understanding of the work of computer scientists: The draw-a-computer-scientist test. In Proceedings of the 2017 ACM SIGCSE technical symposium on computer science education (pp. 279-284). New York, NY: ACM.

Harackiewicz, J. M., Canning, E. A., Tibbetts, Y., Priniski, S. J., \& Hyde, J. S. (2016). Closing achievement gaps with a utility-value intervention: Disentangling race and social class. Journal of Personality and Social Psychology, 111, 745-765.

Harackiewicz, J. M., Rozek, C. S., Hulleman, C. S., \& Hyde, J. S. (2012). Helping parents to motivate adolescents in mathematics and science: An experimental test of a utility-value intervention. Psychological Science, 23, 899-906.

Heilbronner, N. N. (2011). Stepping onto the STEM pathway: Factors affecting talented students' declaration of STEM majors in college. Journal for the Education of the Gifted, $34,876-899$.

Heilman, M. E. (2012). Gender stereotypes and workplace bias. Research in Organizational Behavior, 32, 113-135.

Heyman, G. D., \& Legare, C. H. (2004). Children's beliefs about gender differences in the academic and social domains. Sex Roles, 50, 227-239.

Hillman, S. J., Bloodsworth, K. H., Tilburg, C. E., Zeeman, S. I., \& List, H. E. (2014). K-12 students' perceptions of scientists: Finding a valid measurement and exploring whether 
exposure to scientists makes an impact. International Journal of Science Education, 36, 2580-2595.

Huang, C. (2013). Gender differences in academic self-efficacy: a meta-analysis. European Journal of Psychology of Education, 28, 1-35.

Hulleman, C. S., \& Harackiewicz, J. M. (2009). Promoting interest and performance in high school science classes. Science, 326, 1410-1412.

Hyde, J. S., \& Mertz, J. E. (2009). Gender, culture, and mathematics performance. Proceedings of the National Academy of Sciences, 106, 8801-8807.

Jacobs, J. E. (1991). Influence of gender stereotypes on parent and child mathematics attitudes. Journal of Educational Psychology, 83, 518-527.

Johns, M., Schmader, T., \& Martens, A. (2005). Knowing is half the battle: Teaching stereotype threat as a means of improving women's math performance. Psychological Science, 16, 175-179.

Keller, J. (2007). Stereotype threat in classroom settings: The interactive effect of domain identification, task difficulty and stereotype threat on female students' maths performance. British Journal of Educational Psychology, 77, 323-338.

Kerr, B. A., \& Multon, K. D. (2015). The development of gender identity, gender roles, and gender relations in gifted students. Journal of Counseling \& Development, 93, 183-191.

Koren, P., \& Bar, V. (2009). Pupils' image of 'the scientist' among two communities in Israel: A comparative study. International Journal of Science Education, 31, 2485-2509.

Kurtz-Costes, B., Copping, K. E., Rowley, S. J., \& Kinlaw, C. R. (2014). Gender and age differences in awareness and endorsement of gender stereotypes about academic abilities. European Journal of Psychology of Education, 29, 603-618. 
Leaper, C. (2002). Parenting girls and boys. In M. H. Bornstein (Ed.), Handbook of parenting: Vol. 1: Children and parenting (2nd ed., pp. 189-225). Mahwah, NJ, US: Erlbaum.

Leslie, S. J., Cimpian, A., Meyer, M., \& Freeland, E. (2015). Expectations of brilliance underlie gender distributions across academic disciplines. Science, 347, 262-265.

Losh, S. C. (2010). Stereotypes about scientists over time among US adults: 1983 and 2001. Public Understanding of Science, 19, 372-382.

Losh, S. C., Wilke, R., \& Pop, M. (2008). Some methodological issues with "Draw a Scientist Tests" among young children. International Journal of Science Education, 30, 773-792.

Lubinski, D., Benbow, C. P., \& Kell, H. J. (2014). Life paths and accomplishments of mathematically precocious males and females four decades later. Psychological Science, 25, 2217-2232.

Martin, C. L., \& Ruble, D. (2004). Children's search for gender cues: Cognitive perspectives on gender development. Current Directions in Psychological Science, 13, 67-70.

Master, A., Cheryan, S., \& Meltzoff, A. N. (2016). Computing whether she belongs: Stereotypes undermine girls' interest and sense of belonging in computer science. Journal of Educational Psychology, 108, 424-437.

Master, A., Cheryan, S., \& Meltzoff, A. N. (2017). Social group membership increases STEM engagement among preschoolers. Developmental Psychology, 53, 201-209.

McClelland, D. C. (1985). How motives, skills, and values determine what people do. American Psychologist, 40, 812-825.

Mendez, L. M. R., \& Crawford, K. M. (2002). Gender-role stereotyping and career aspirations: A comparison of gifted early adolescent boys and girls. Journal of Secondary Gifted Education, 13, 96-107. 
Mercier, E. M., Barron, B., \& O'Connor, K. M. (2006). Images of self and others as computer users: The role of gender and experience. Journal of Computer Assisted Learning, 22, $335-348$.

Meyer, M., Cimpian, A., \& Leslie, S. J. (2015). Women are underrepresented in fields where success is believed to require brilliance. Frontiers in Psychology, 6, 235.

Miller, D. I., Nolla, K. M., Eagly, A. H., \& Uttal, D. H. (2018). The development of children's gender-science stereotypes: A meta-analysis of 5 decades of US draw-a-scientist studies. Child Development. Advance online publication. doi:10.1111/cdev.13039

Nagy, G., Watt, H. M., Eccles, J. S., Trautwein, U., Lüdtke, O., \& Baumert, J. (2010). The development of students' mathematics self-concept in relation to gender: Different countries, different trajectories? Journal of Research on Adolescence, 20, 482-506.

National Academy of Engineering. (2017). NAE Grand Challenges for Engineering. Retrieved 25 July 2017, from http://www.engineeringchallenges.org/.

National Association for Gifted Children. (2015). 2014-2015 state of the states in gifted education: Policy and practice data [Data file]. Retrieved from http://www.nagc.org/resources-publications/gifted-state/2014-2015-state-states-giftededucation.

National Science Board (US). (2010). Preparing the next generation of stem innovators: Identifying and developing our nation's human capital. Retrieved from https://www.nsf.gov/nsb/publications/2010/nsb1033.pdf.

National Science Foundation, National Center for Science and Engineering Statistics. (2016). Doctorate Recipients from U.S. Universities: 2015. Special Report NSF 17-306. Arlington, VA. Retrieved from www.nsf.gov/statistics/2017/nsf17306/. 
Newton, D. P., \& Newton, L. D. (1992). Young children's perceptions of science and the scientist. International Journal of Science Education, 14, 331-348.

Newton, D. P., \& Newton, L. D. (1998). Primary children's conceptions of science and the scientist: is the impact of a National Curriculum breaking down the stereotype? International Journal of Science Education, 20, 1137-1149.

Nguyen, H. H., \& Ryan, A. M. (2008). Does stereotype threat affect cognitive ability test performance of minorities and women? A meta-analytic review of experimental evidence. Journal of Applied Psychology, 93, 1314-1335.

Niedenthal, P. M., Cantor, N., \& Kihlstrom, J. F. (1985). Prototype matching: A strategy for social decision making. Journal of Personality and Social Psychology, 48, 575-584.

Nosek, B. A., Smyth, F. L., Hansen, J. J., Devos, T., Lindner, N. M., Ranganath, K. A., ... \& Banaji, M. R. (2007). Pervasiveness and correlates of implicit attitudes and stereotypes. European Review of Social Psychology, 18, 36-88.

Osborne, J. W., \& Walker, C. (2006). Stereotype threat, identification with academics, and withdrawal from school: Why the most successful students of colour might be most likely to withdraw. Educational Psychology, 26, 563-577.

Oyserman, D., Terry, K., \& Bybee, D. (2002). A possible selves intervention to enhance school involvement. Journal of Adolescence, 25, 313-326.

Pansegrau, P. (2008). Stereotypes and images of scientists in fiction films. In B. R. Hüppauf \& P. Weingart (Eds.), Science images and popular images of the sciences (pp. 257-266). New York, NY: Routledge

Penner, A. M. (2008). Gender differences in extreme mathematical achievement: An international perspective on biological and social factors. American Journal of Sociology, 


\section{4, S138-S170.}

Rattan, A., Savani, K., Komarraju, M., Morrison, M. M., Boggs, C., \& Ambady, N. (in press). Meta-lay Theories of Scientific Potential Drive Underrepresented Students' Sense of Belonging to Science, Technology, Engineering, and Mathematics (STEM). Journal of Personality and Social Psychology. Retrieved from https://www.krishnasavani.com/wordpress/wpcontent/uploads/2017/12/Rattan_Savani_et_al_2018.pdf.

Raty, H., \& Snellman, L. (1997). Children's images of an intelligent person. Journal of Social Behavior and Personality, 12, 773-784.

Régner, I., Steele, J. R., Ambady, N., Thinus-Blanc, C., \& Huguet, P. (2014). Our future scientists: A review of stereotype threat in girls from early elementary school to middle school. Revue Internationale de Psychologie Sociale, 27, 13-51.

Roberts, S. O., Gelman, S. A., \& Ho, A. K. (2017). So it is, so it shall be: Group regularities license children's prescriptive judgments. Cognitive Science, 41, 576-600.

Robinson-Cimpian, J. P., Lubienski, S. T., Ganley, C. M., \& Copur-Gencturk, Y. (2014). Teachers' perceptions of students' mathematics proficiency may exacerbate early gender gaps in achievement. Developmental Psychology, 50, 1262-1281.

Rommes, E., Overbeek, G., Scholte, R., Engels, R., \& De Kemp, R. (2007). 'I'm not interested in computers': Gender-based occupational choices of adolescents. Information, Community and Society, 10, 299-319.

Schmader, T., Johns, M., \& Barquissau, M. (2004). The costs of accepting gender differences: The role of stereotype endorsement in women's experience in the math domain. Sex Roles, 50, 835-850. 
Schmader, T., Johns, M., \& Forbes, C. (2008). An integrated process model of stereotype threat effects on performance. Psychological Review, 115, 336-356.

Schmidt, M. F., Butler, L. P., Heinz, J., \& Tomasello, M. (2016). Young children see a single action and infer a social norm: Promiscuous normativity in 3-year-olds. Psychological Science, 27, 1360-1370.

Schott, G., \& Selwyn, N. (2000). Examining the "male, antisocial" stereotype of high computer users. Journal of Educational Computing Research, 23, 291-303.

Simpkins, S. D., Davis-Kean, P. E., \& Eccles, J. S. (2006). Math and science motivation: A longitudinal examination of the links between choices and beliefs. Developmental psychology, 42, 70.

Skinner, A. L., Meltzoff, A. N., \& Olson, K. R. (2017). “Catching” social bias: Exposure to biased nonverbal signals creates social biases in preschool children. Psychological Science, 28, 216-224.

Smith, J. L., Lewis, K. L., Hawthorne, L., \& Hodges, S. D. (2013). When trying hard isn’t natural: Women's belonging with and motivation for male-dominated STEM fields as a function of effort expenditure concerns. Personality and Social Psychology Bulletin, 39, 131-143.

Snyder, K. E., Malin, J. L., Dent, A. L., \& Linnenbrink-Garcia, L. (2014). The message matters: The role of implicit beliefs about giftedness and failure experiences in academic selfhandicapping. Journal of Educational Psychology, 106, 230-241.

Song, J., \& Kim, K. S. (1999). How Korean students see scientists: The images of the scientist. International Journal of Science Education, 21, 957-977.

Spelke, E. S. (2005). Sex differences in intrinsic aptitude for mathematics and science?: A 
critical review. American Psychologist, 60, 950-958.

Spencer, S. J., Logel, C., \& Davies, P. G. (2016). Stereotype threat. Annual Review of Psychology, 67, 415-437.

Spencer, S. J., Steele, C. M., \& Quinn, D. M. (1999). Stereotype threat and women's math performance. Journal of Experimental Social Psychology, 35, 4-28.

Steele, C. M. (1997). A threat in the air: How stereotypes shape intellectual identity and performance. American Psychologist, 52, 613-629.

Steele, J. (2003). Children's gender stereotypes about math: The role of stereotype stratification. Journal of Applied Social Psychology, 33, 2587-2606.

Stephens-Davidowitz, S. (2014, January 19). Google, tell me. Is my son a genius? The New York Times. p. SR6. Retrieved from https://www.nytimes.com/2014/01/19/opinion/sunday/ google-tell-me-is-my-son-a-genius.html.

Stoeger, H., Duan, X., Schirner, S., Greindl, T., \& Ziegler, A. (2013). The effectiveness of a oneyear online mentoring program for girls in STEM. Computers \& Education, 69, 408-418.

Storage, D., Horne, Z., Cimpian, A., \& Leslie, S. J. (2016). The frequency of "brilliant" and "genius" in teaching evaluations predicts the representation of women and African Americans across fields. PLOS ONE, 11, e0150194.

Su, R., Rounds, J., \& Armstrong, P. I. (2009). Men and things, women and people: A metaanalysis of sex differences in interests. Psychological Bulletin, 135, 859-884.

Tenenbaum, H. R., \& Leaper, C. (2003). Parent-child conversations about science: The socialization of gender inequities? Developmental Psychology, 39, 34-47.

United States Department of Education. (2000). Civil Rights Data Collection, 2000 National and State Estimations, National total [Data file]. Retrieved from 
http://ocrdata.ed.gov/StateNationalEstimations/Projections_2000.

Voyer, D., \& Voyer, S. D. (2014). Gender differences in scholastic achievement: A metaanalysis. Psychological Bulletin, 140, 1174-1204.

Walton, G. M., \& Cohen, G. L. (2007). A question of belonging: Race, social fit, and achievement. Journal of Personality and Social Psychology, 92, 82-96.

Walton, G. M., \& Cohen, G. L. (2011). A brief social-belonging intervention improves academic and health outcomes of minority students. Science, 331, 1447-1451.

Walton, G. M. (2014). The new science of wise psychological interventions. Current Directions in Psychological Science, 23, 73-82.

Wang, M. T., Eccles, J. S., \& Kenny, S. (2013). Not lack of ability but more choice: Individual and gender differences in choice of careers in science, technology, engineering, and mathematics. Psychological science, 24, 770-775.

Wigfield, A., \& Eccles, J. S. (2000). Expectancy-value theory of achievement motivation. Contemporary Educational Psychology, 25, 68-81.

Yeager, D. S., Purdie-Vaughns, V., Garcia, J., Apfel, N., Brzustoski, P., Master, A., ... \& Cohen, G. L. (2014). Breaking the cycle of mistrust: Wise interventions to provide critical feedback across the racial divide. Journal of Experimental Psychology: General, 143, 804.

Yeager, D. S., Romero, C., Paunesku, D., Hulleman, C. S., Schneider, B., Hinojosa, C., ... \& Trott, J. (2016). Using design thinking to improve psychological interventions: The case of the growth mindset during the transition to high school. Journal of Educational Psychology, 108, 374-391. 
Yeager, D. S., \& Walton, G. M. (2011). Social-psychological interventions in education: They’re not magic. Review of Educational Research, 81, 267-301.

Yeager, D. S., Walton, G. M., Brady, S. T., Akcinar, E. N., Paunesku, D., Keane, L., ... \&

Gomez, E. M. (2016). Teaching a lay theory before college narrows achievement gaps at scale. Proceedings of the National Academy of Sciences, 113, E3341-E3348.

Ziegler, A., \& Heller, K. A. (2000). Effects of an attribution retraining with female students gifted in physics. Journal for the Education of the Gifted, 23, 217-243. 
Table 1

Potential Strategies for Encouraging Pursuit of and Success in STEM Among (Gifted) Girls

1. COMBAtTing THE NeGATIVE STEREOTYPeS ABOUt GIRLS’ ABILITIES:

1.1. Strategies that may inoculate girls against these stereotypes ("psychological vaccines"):

1.1.1. Instill a growth mindset: the belief that abilities can be improved with effort, strategies, and mentoring

Note: It's important to convey that effort and strategies build ability (rather than compensate for lack of ability), and that this is true for everyone (not just girls). It's also useful to adopt a positive, constructive attitude toward failure; failure is a valuable learning opportunity.

1.1.2. Expose girls to successful female role models in STEM

Note: It's important to present role models in a way that allows girls to feel similar to them and identify with them

\subsection{Strategies that may make the STEM environment less threatening}

1.2.1. Acknowledge the existence of the negative stereotypes but deny their truth

Note: It's important to avoid statements that frame boys as the reference point (e.g., "girls can do math as well as

boys"). Instead, use statements whose structure places boys and girls on an equal footing (e.g., "there is no difference in how well boys and girls can perform in math").

1.2.2. Acknowledge the toll that stereotypes might take on girls' performance

1.2.3. Include physical reminders of women's STEM success in the lab or classroom (e.g., portraits of female scientists)

2. COMBATTING THE STEREOTYPES ABOUT THE PEOPLE IN STEM:

2.1. Strategies to revise stereotypes of scientists and engineers as people

2.1.1. Provide girls with opportunities to interact with non-stereotypical people in STEM

2.2. Strategies to revise stereotypes of the work that scientists and engineers do

2.2.1. Portray work in STEM as helpful, altruistic, and community-oriented

2.2.2. Provide opportunities to do STEM-related activities as part of a group 